$\begin{array}{ll}\text { Hiroyuki Yano, MD } & \text { Mitsuyo Kinjo, MD, MPH } \\ \text { Division of Rheumatology, Department } \\ \text { of Medicine, Okinawa Chubu Hospital, } \\ \begin{array}{l}\text { Oivision of Rheumatology, Department } \\ \text { of Medicine, Okinawa Chubu Hospital, } \\ \text { Okinawa, Japan }\end{array}\end{array}$

\title{
Tumoral calcinosis
}

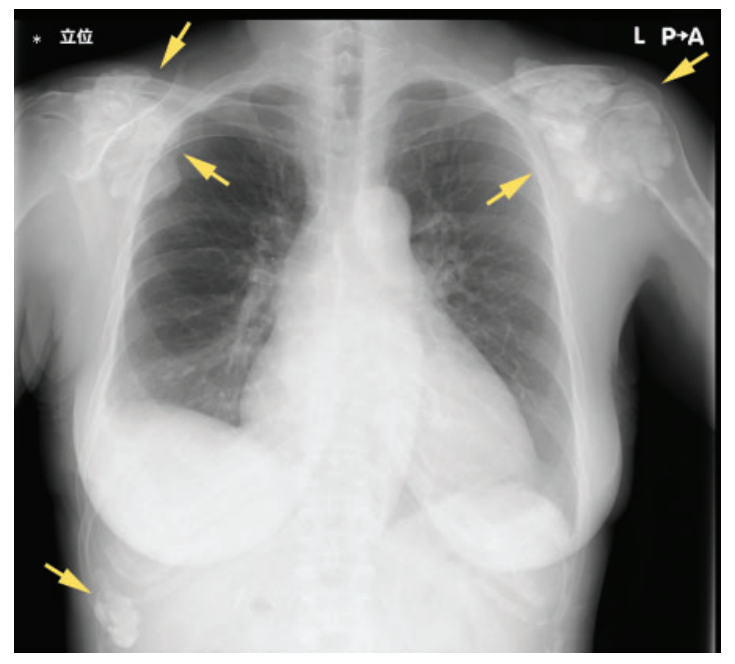

Figure 1. Chest radiography showed large, irregular, calcified masses (arrows) adjacent to the shoulders and beneath the right lower ribs.

management
includes
restricting
dietary
calcium and
phosphorus,
using low
calcium
dialysate,
and giving
non-calcium-
containing
phosphate
binders

A 47-YEAR-OLD WOMAN PRESENTED to our hospital with dyspnea and mild hip pain on ambulation. Chest radiography revealed multiple calcified masses on both shoulders.

She had received peritoneal dialysis for 3.5 years because of chronic lupus nephritis. Her prescribed medications included prednisolone $5 \mathrm{mg}$ daily, alfacalcidol $1 \mu \mathrm{g}$ daily, and evocalcet (a new calcimimetic approved in Japan for secondary hyperparathyroidism in patients undergoing dialysis) $1 \mathrm{mg}$ daily. She had an unremarkable family medical history, and she did not use tobacco or alcohol.

On physical examination, the jugular veins were distended, and heart and lung auscultation revealed an S3 gallop and bibasilar crackles. There were no palpable masses or tenderness of the shoulders, but range of motion of hip joints was limited.

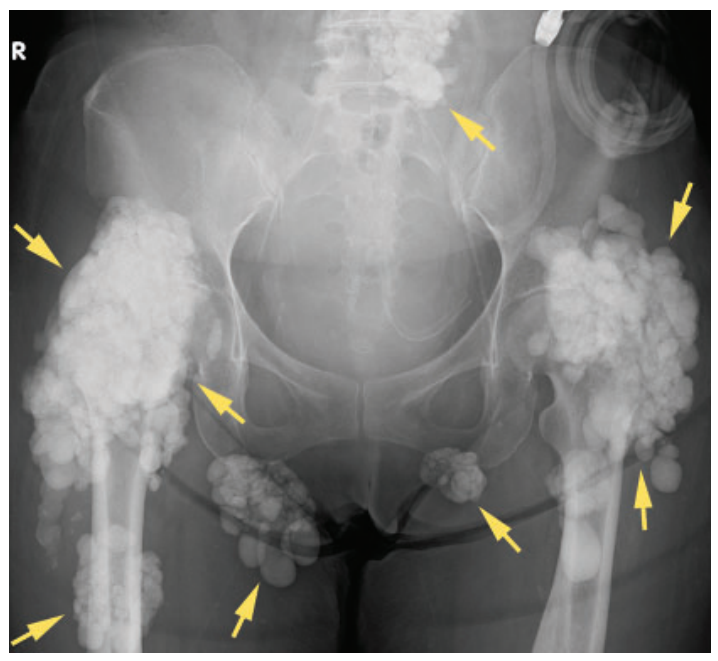

Figure 2. Pelvic radiography showed large, irregular, calcified masses (arrows) adjacent to the left lower lumbar spine, hip joints, and over both ischial tuberosities. lows:

Results of laboratory studies were as fol-

- Average serum calcium $7.5 \mathrm{mg} / \mathrm{dL}$ (reference range 8.8-10.1)

- Phosphate $4.8 \mathrm{mg} / \mathrm{dL}(2.7-4.6)$

- Blood urea nitrogen $35 \mathrm{mg} / \mathrm{dL}$ (8-20)

- Serum creatinine $6.9 \mathrm{mg} / \mathrm{dL}(0.46-0.79)$

- Total protein $5.5 \mathrm{~g} / \mathrm{dL}(6.6-8.1)$

- Albumin $2.7 \mathrm{~g} / \mathrm{dL}(4.1-5.1)$

- Intact parathyroid hormone $390 \mathrm{pg} / \mathrm{mL}$ (10-60)

- Normal white blood cell count.

Chest and hip radiographs demonstrated cardiomegaly with pulmonary congestion, as well as large, irregular, calcified masses adjacent to both shoulders, below the right lower ribs (Figure 1), on the left side of the lower lumbar spine, at the hip joints, and superimposed over both ischial tuberosities (Figure 2).

Multiple calcified masses on radiography suggested tumoral calcinosis, the differential 
diagnosis of which includes calcific tendonitis, synovial osteochondromatosis, and osteosarcoma. Extensive calcification beyond the tendons and synovia of multiple joints made these conditions less likely, and osteosarcoma usually affects children and adolescents. ${ }^{1}$ In our patient's case, the diagnosis was tumoral calcinosis associated with chronic kidney disease, along with congestive heart failure.

She began temporary hemodialysis, which improved her heart failure symptoms, and then peritoneal dialysis was reintroduced with an increase in frequency. Her evocalcet was increased to $2 \mathrm{mg}$ daily.

\section{FEATURES OF TUMORAL CALCINOSIS}

Tumoral calcinosis is an uncommon disorder characterized by calcium salt deposition around large joints, resulting in irregular, large, lobulated calcified masses. ${ }^{2}$

Histologic examination of the mass demonstrates extensive amorphous calcium deposits within a fibrous stroma with giant multinucleated foreign-body cells and inflammatory infiltrates. ${ }^{3}$

Tumoral calcinosis is divided into primary and secondary types, and chronic kidney disease is the leading cause of the secondary type. ${ }^{4}$ The incidence of secondary tumoral calcinosis in patients undergoing peritoneal

\section{REFERENCES}

1. Misaghi A, Goldin A, Awad M, Kulidjian AA. Osteosarcoma: a comprehensive review. SICOT J 2018; 4:12. doi:10.1051/sicotj/2017028

2. Karaca L, Polat G, Sade R, Yüce I, Ogul H, Kantarci M. Nontraumatic tumoral calcinosis. Joint Bone Spine 2017; 84(4):491. doi:10.1016/j.jbspin.2016.06.009

3. Chi D, Kamochi H, Sunaga A, et al. Tumoral calcinosis: a giant tumoral mass in the shoulder joint of a dialysis patient. Plast Reconstr Surg Glob Open 2018 ;6(4):e1730. doi:10.1097/GOX.0000000000001730

4. Fathi I, Sakr M. Review of tumoral calcinosis: a rare clinico-pathological entity. World J Clin Cases 2014; dialysis has been estimated as $1.6 \% .^{5}$

Although the precise mechanism is unknown, risk factors include hypercalcemia, hyperphosphatemia, increased calcium-phosphate product, hyperparathyroidism, calciumcontaining phosphate binders, and activated vitamin D. $^{6}$

Common clinical manifestations are joint tenderness, limited range of motion of joints, and skin ulcerations. In one report, $14 \%$ of patients ( 1 of 7 ) with secondary tumoral calcinosis had no symptoms. ${ }^{5}$

\section{TREATMENT OPTIONS}

Treatment should focus on correcting risk factors to optimize calcium and phosphate homeostasis. Medical management includes restricting dietary calcium and phosphorus, using low-calcium dialysate, and giving noncalcium-containing phosphate binders.

Excision of calcified masses is indicated in cases refractory to conservative medical care. ${ }^{6}$ Renal transplant has been reported to produce complete remission., 5 Parathyroidectomy has been tried but reported to be unsatisfactory.

\section{DISCLOSURES}

The authors report no relevant financial relationships which, in the context of their contributions, could be perceived as a potential conflict of interest.

2(9):409-414. doi:10.12998/wjcc.v2.i9.409

5. Chu HY, Chu P, Lin YF, Chou HK, Lin SH. Uremic tumoral calcinosis in patients on peritoneal dialysis: clinical, radiologic, and laboratory features. Perit Dial Int 2011; 31(4):430-439. doi:10.3747/pdi.2009.00250

6. Zhou H, Yang M, Zou Y. Uraemic tumoral calcinosis in a peritoneal dialysis patient. Intern Med J 2018; 48(12):1544-1546. doi:10.1111/imj.14130

Address: Mitsuyo Kinjo, MD, MPH, Division of Rheumatology, Department of Internal Medicine, Okinawa Chubu Hospital, 281 Miyazato, Uruma City, Okinawa, 904-2293, Japan; kinjomitsuyo@gmail.com 